\title{
A Regulação do Agir Decisório Disruptivo no Judiciário Brasileiro e a Observância do Princípio da Precaução: Juiz Natural ou "Juiz
} ARtificial"?

\section{The Regulation of Disruptive Decisions in Brazilian Judicial Power and the Application of the Precautionary Principle: Natural Judge OR "ARTIFICIAL JUDGE"?}

\section{La Regulación de la Decisión Disruptiva en el Poder Judicial Brasileño y la Aplicación del Principio Precaucionario: ¿Juez Natural o "Juez} Artificial"?

Rafael Gonçalves Fernandes Liziane Paixão Silva Oliveira ${ }^{* *}$

1 Introdução. 2 A evolução e as incertezas da inteligência artificial. 3 A LGPD
como estratégia regulatória da inteligência artificial. 4 O recorte setorial: a
aplicação da inteligência artificial no poder judiciário. $5 \mathrm{O}$ panorama

" Doutorando e Mestre em Direito no Centro Universitário de Brasília - UniCEUB, Brasil. Bolsista do Programa CAPES/Prosup. Brasília, DF, BR. E-mail: <rafaelfernandes.dto@gmail.com>. https://orcid.org/0000-0003-2474-6635

** Doutora em Direito Internacional pela Université d'Aix-Marseille III, Mestre em Direito pela Universidade de Brasília, Professora Titular do Programa de Mestrado e Doutorado em Direito do Centro Universitário de Brasília (UniCEUB), Professora Colaboradora no Programa de Mestrado da Universidade Tiradentes (UNIT) e Professora da Faculdade de Direito da Universidade de Vila Velha (UVV). Brasilia, DF, BR. E-mail: <liziane.oliveira@ceub.edu.br>. https://orcid.org/0000-0002-62666073 
A regulação do agir decisório disruptivo no judiciário brasileiro e a observância do princípio da precaução: juiz natural ou "juiz artificial"?

"precaucional" no desenvolvimento de robôs decisores. 6 Conclusão. Referências.

\section{RESUMO}

Objetivo: $O$ presente artigo científico tem como objetivo abordar a inteligência artificial (IA) no seu aspecto regulatório multifacetado, delineando como hipótese central que, apesar de inexistir no Brasil uma legislação específica, a LGPD parece ter regulado alguns aspectos dessa nova tecnologia, o que torna possível utilizá-la como diretriz normativa, conjuntamente com a construção teórica do princípio da precaução, na promoção da utilização segura da IA no Poder Judiciário brasileiro.

Metodologia: A opção metodológica adotada neste ensaio situa-se nos limites da linha jurídico-dogmática e emprega o raciocínio dedutivo. Em decorrência da baixa produção de pesquisas científicas sobre a temática no cenário nacional, o caráter exploratório foi empregado para expandir as buscas por materiais produzidos pela literatura estrangeira especializada. Trata-se, além disso, de uma pesquisa documental e de levantamento.

Resultados: Identificou-se a importância da LGPD como marco regulatório da IA nos tribunais brasileiros, uma vez que tal Lei poderá funcionar como estratégia implementadora de uma nova visão baseada no desenvolvimento tecnológico seguro. Apesar de inexistir uma conclusão definitiva para o tema, também foi possível comprovar a importância da carga teórica e histórica do princípio da precaução como ferramental jurídico apto a minimizar e/ou contornar os possíveis efeitos negativos da IA no Judiciário.

Contribuições: A contribuição central desta pesquisa está em identificar os potenciais riscos na utilização da IA no Judiciário e indicar leituras alternativas que possam auxiliar na prevenção desses efeitos indesejados aos jurisdicionados, tendo como base construções teóricas que iluminem os caminhos do desenvolvimento tecnológico seguro e prudente.

Palavras-chave: Lei Geral de Proteção de Dados (LGPD). Poder Judiciário. Decisões automatizadas. Sociedade de Risco. Inteligência Artificial no Judiciário. Inteligência Artificial brasileira.

\section{ABSTRACT}

Objective: The objective of this scientific article is to address artificial intelligence (AI) in the multifaceted regulatory aspect. The central hypothesis is that the Brazilian General Data Protection Law (LGPD) seems to have regulated some aspects of this new technology, even though there is no specific legislation in Brazil. This view makes it possible to use that Law as a normative guideline, combined with the precautionary 
principle, in promoting the safe use of AI in the Brazilian judiciary.

Methodology: The methodological option adopted is located within the limits of the legal-dogmatic line and uses deductive reasoning. Due to the low production of scientific research in the national scenario, the authors used the exploratory methodology to expand the search for materials in the international specialized literature. It is research and documentary survey.

Results: The importance of LGPD is to use it as an initial regulatory framework for AI in Brazilian Courts since this Law can act as a strategy to implement a new vision based on secure technological development. There is no definitive conclusion to the topic. However, it was also possible to prove the importance of the theoretical and historical burden of the precautionary principle as a legal instrument capable of minimizing and/or circumventing the possible negative effects in the application of this new technology.

Contributions: The central contribution of this research is to identify the potential risks of the use of $\mathrm{AI}$ in the Judiciary and to indicate alternative readings that can help in the solution of these undesirable effects to the jurisdictions. The basis of this vision is in the theoretical constructions that can illuminate the paths of security and prudent technological development.

Keywords: General Data Protection Law (LGPD). Judiciary Branch. Automated decisions. Risk Society. Artificial Intelligence in the Judiciary. Brazilian Artificial Intelligence.

\section{RESUMEN}

Objetivo: El propósito de este artículo científico es abordar la inteligencia artificial (IA) en su aspecto regulatorio multifacético, planteando como hipótesis central que si bien no existe una legislación específica en Brasil, la LGPD parece haber regulado algunos aspectos de esta nueva tecnología, lo que la convierte en es posible utilizarlo como directriz normativa, junto con la construcción teórica del principio de precaución, para promover el uso seguro de la IA en el Poder Judicial brasileño.

Metodología: La opción metodológica adoptada en este ensayo se sitúa dentro de los límites de la línea jurídico-dogmática y emplea el razonamiento deductivo. Debido a la baja producción de investigación científica sobre el tema en el escenario nacional, se utilizó el carácter exploratorio para ampliar la búsqueda de materiales producidos por literatura extranjera especializada. Es una investigación y una encuesta documental. 
A regulação do agir decisório disruptivo no judiciário brasileiro e a observância do princípio da precaução: juiz natural ou "juiz artificial"?

Resultados: Se identificó la importancia de la LGPD como marco regulatorio para la IA en los tribunales brasileños, ya que esta Ley puede actuar como una estrategia para implementar una nueva visión basada en el desarrollo tecnológico seguro. Cabe señalar que si bien no existe una conclusión definitiva para el tema, también se pudo comprobar la importancia de la carga teórica e histórica del principio de precaución como herramienta jurídica capaz de minimizar y/o eludir los posibles efectos negativos en la aplicación de esta nueva tecnología.

Contribuciones: El aporte central de esta investigación es identificar los riesgos potenciales en el uso de la IA en el Poder Judicial e indicar lecturas alternativas que puedan ayudar en la prevención de estos efectos no deseados a la jurisdicción, a partir de construcciones teóricas que iluminen los caminos de un desarrollo tecnológico seguro y prudente.

Palabras clave: Ley General de Protección de Datos (LGPD). Poder Judicial. Decisiones automatizadas. Sociedad de riesgo. Inteligencia artificial en el poder judicial. Inteligencia Artificial Brasileña.

\section{INTRODUÇÃO}

As inovações advindas da Inteligência Artificial (IA) já estão presentes em diferentes setores da vida humana e das instituições públicas e privadas. Atualmente, é possível utilizar assistentes virtuais programadas para facilitar a realização de tarefas rotineiras, adquirir robôs que executam pequenas atividades domésticas e conectar múltiplos equipamentos eletrônicos de uma residência ou de um usuário. Também é possível obter uma experiência personalizada na utilização de diversas plataformas digitais, que empregam algoritmos inteligentes para oferecer bens de consumo específicos aos seus usuários. Por outro lado, em uma visão institucionalista, a IA também oferece novas soluções para a "arquitetura" do Direito e dos Tribunais, com a automatização de atividades repetitivas na feitura de petições e de decisões judiciais, bem como na perfilização de magistrados e de agentes demandados em processos judiciais. A IA é capaz de transformar uma grande quantidade de dados desconexos em informações valiosas e essenciais tanto para os usuários comuns quanto para usuários corporativos.

Trata-se de uma tecnologia futurista, que ultrapassou as telas do cinema e se mostra como uma área essencial ao sucesso econômico da sociedade atual. É certo que parte dela ainda não saiu dos laboratórios da Ciência da Computação e permanece na fase de ensaios "comportamentais" dos algoritmos inovadores. Todavia, já existem tecnologias capazes de executar tarefas características da inteligência humana, tais como o aprendizado de máquinas e a tomada de decisão autônoma. A Inteligência Artificial, 
como ramo dedicado à criação de programas de computador, consiste em uma tecnologia disruptiva, ${ }^{1}$ que converge uma série de conhecimentos científicos de distintas áreas, o que exige uma abordagem interdisciplinar da temática.

Diante da complexidade e da pervasividade de aplicações da Inteligência Artificial, o presente artigo científico traz como enfoque setorial a utilização dessa tecnologia no âmbito dos tribunais. A problemática central, por sua vez, está em verificar a possibilidade de adotar a Lei Geral de Proteção de Dados Pessoais (LGPD) como diretriz normativa e orientadora do desenvolvimento seguro dessa nova tecnologia no Judiciário brasileiro. Tal leitura também é lastreada na aplicação do princípio da precaução nesse cenário disruptivo, frente às incertezas técnicas e jurídicas que ele apresenta.

A abordagem do tema perpassa por uma breve contextualização da Inteligência Artificial, por meio da exposição de questões técnicas centrais e dos seus impactos positivos e negativos na sociedade. Essa narrativa é seguida da exposição da LGPD como marco regulatório transversal da Inteligência Artificial (regulamentação), bem como do desenvolvimento de novos padrões técnicos combinados entre sociedades empresárias do ramo (autorregulação). Em seguida, são apontados exemplos concretos da IA no setor da administração judiciária e as expectativas do mercado nesse novo nicho tecnológico. Por fim, realiza-se uma excursão na literatura sobre o princípio da precaução, com o objetivo de identificar a possibilidade de aplicá-lo, como o principal vetor teórico, no desenvolvimento seguro e sustentável dessa nova tecnologia.

Esse caminhar é pautado nos limites da linha jurídico-dogmática. Isso porque se busca compreender as "[...] relações normativas nos vários campos do Direito e com a avaliação das estruturas interiores ao ordenamento jurídico.” (GUSTIN, 2006, p. 21). Nesse ponto, o diálogo das fontes auxiliará na interpretação sistemática das normas correlatas ao tema (MARQUES, 2017, p. 104). Contudo, essas constatações não afastam a necessidade de pensar as relações normativas no seu aspecto externo. É justamente a opção realizada nas seções 2 e 4, que abordam uma vertente externa ao Direito, sobre os aspectos técnicos da Inteligência Artificial com aporte na literatura especializada.

\footnotetext{
${ }^{1}$ Para a OCDE, as tecnologias consideradas disruptivas possuem duas características principais: a) o potencial de modificar drasticamente o formato de funcionamento dos mercados; e b) a capacidade de introduzir novos produtos e novos processos, bem como de instituir novos modelos de negócios diferenciados daqueles já existentes. A Organização entende que, apesar de não existir uma definição singular de "inovação disruptiva", alguns pontos característicos auxiliam na sua delimitação, tendo em vista que: a) elas advêm de novas sociedades empresárias ou já existentes no mercado e modificam as estratégias comerciais de grandes setores; b) visam a oferecer novas ferramentas para diminuir custos e otimizar tarefas e aumentam os benefícios destinados ao consumidor final; e c) têm o potencial de desequilibrar ou extinguir modelos de negócios existentes, aumentando a competitividade entre as sociedades empresárias (OCDE, 2015, p. 3).
} 
A regulação do agir decisório disruptivo no judiciário brasileiro e a observância do princípio da precaução: juiz natural ou "juiz artificial"?

\section{A EVOLUÇÃO E AS INCERTEZAS DA INTELIGÊNCIA ARTIFICIAL}

Os primeiros estudos substanciais em Inteligência Artificial foram realizados por Alan Turing em 1941. Sob a denominação de machine intelligence, o cientista já previa que as máquinas poderiam resolver problemas práticos através da adoção de esquemas preestabelecidos pelos seus programadores. Contudo, as pesquisas modernas em IA apenas começaram em 1956, em New Hampshire, em um programa acadêmico de verão da Dartmouth College. Até alcançar o mercado de consumo em massa, haveria muitos desafios e altos custos, que acabam retardando a sua implementação (COPELAND, 2004).

Entre as principais características atuais da IA, pode-se citar:

a) o monitoramento de uma grande quantidade de dados (pessoais ou não), produzidos por pessoas e/ou por máquinas;

b) o aprendizado dos sistemas de computador, para extrair informações úteis desse conglomerado de dados;

c) a interpretação de diferentes padrões de dados não estruturados, presentes em textos, imagens, áudios e vídeos e;

d) a interação ativa entre pessoas naturais e sistemas (softwares) e/ou máquinas (hardwares) (ITIF, 2018).

A doutrina especializada entende que existem dois tipos distintos de Inteligência Artificial. A primeira está ligada à capacidade limitada dos sistemas inteligentes de executar tarefas previamente definidas pelos seus desenvolvedores (Narrow AI). Já a segunda possui uma capacidade ilimitada de atingir objetivos complexos e de criar ou aperfeiçoar novos objetivos de maneira autônoma, mesmo em situações de incerteza ou imprecisão (General AI). A tendência apontada pela doutrina está no crescimento exponencial da segunda categoria (TURNER, 2019, p. 6).

Se os algoritmos são o motor da Inteligência Artificial, os dados pessoais são o combustível que alimenta tal desenvolvimento tecnológico. Essa tecnologia possibilita o processamento de uma infinidade de dados, identificando correlações entre eles e gerando novas informações, que talvez não fossem alcançadas sem a ajuda dos robôs (ERNST, 2020, p. 53). Esse conglomerado de dados, que são colhidos por meio de inúmeros equipamentos eletrônicos, também pode ser utilizado no aperfeiçoamento do "aprendizado de máquinas". É nesse ponto que se concentra o principal avanço pervasivo da IA, ${ }^{2}$ capaz de modificar radicalmente milhares de atividades e setores econômicos, inclusive as atividades burocráticas do Estado (SURDEN, 2014).

\footnotetext{
${ }^{2}$ Não existe um conceito unânime de IA. No âmbito europeu, a Comissão Europeia entendeu que "Inteligência Artificial (IA) refere-se aos sistemas que apresentam um comportamento inteligente, analisando o seu ambiente e tomando medidas - com um determinado nível de autonomia - para atingir objetivos específicos." (UNIÃO EUROPEIA, 2018).
} 
Essa "revolução" baseada em dados cria um nicho de mercado inédito e apto a minerá-los, transformando-os em itens comercializáveis (produtos e serviços inteligentes ou em publicidade digital), tanto para os usuários profissionais quanto para os não profissionais. Todavia, essa nova realidade tecnológica reforça também a concepção de que se vive em uma "sociedade de risco" sujeita aos infortúnios e percalços encontrados nos potenciais riscos dos sistemas inteligentes, que podem gerar danos materiais e imateriais, individuais e coletivos (BECK, 1998, 2018). Essa ampla capacidade tecnológica do agir de maneira autônoma e imprevisível direcionou a atenção do Direito aos aspectos legais do seu desenvolvimento, principalmente sobre a capacidade de o ordenamento jurídico absorver o rápido avanço científico e tecnológico.

A Inteligência Artificial usufrui de um crescimento instantâneo do mercado baseado em dados. Estima-se que, para cada pessoa no mundo, são criados em média 1,7 MB (Megabytes) de dados por segundo (DOMO, 2018). Trata-se de um conglomerado denominado de Big Data. ${ }^{3}$ Nem todos consistem em dados pessoais, mas grande parte desse volume refere-se às escolhas feitas pelos usuários em diversas plataformas digitais, tais como Google, WhatsApp, Facebook, Uber, Spotify, Instagram, Skype, Twitter, YouTube, LinkedIn, Snapchat, Netflix, Amazon, Tumblr, Tinder, entre outros. Por exemplo, uma das grandes varejistas do comércio virtual colhe por hora mais de 2,5 petabytes de dados dos seus clientes ou potenciais clientes (MCAFEE; BRYNJOLFSSON, 2012).

O The World Privacy Forum, uma organização privada sem fins lucrativos dedicada à pesquisa científica na era digital, estimou que já havia em 2014 cerca de quatro mil bases de dados habilitadas a coletar informações pessoais dos usuários. Esse interesse excessivo das sociedades empresárias no processamento de dados é representado pela possibilidade de monetizá-los. Pesquisas indicam que a Inteligência Artificial pode auxiliar nessa tarefa, além de aumentar o Produto Interno Bruto (PIB) global em 14\% até o ano de 2030, o que equivalerá a um aumento de \$15,7 (quinze vírgula sete) trilhões de dólares na economia (DIXON; GELLMAN, 2014).

Nesse cenário, a principal tarefa da Inteligência Artificial é organizar e estruturar os dados pessoais. Por esse motivo, ela está sendo considerada uma tecnologia estratégica do século XXI. É nesse sentido que Schwab (2016, p. 30) afirma que a

\footnotetext{
${ }^{3}$ Apesar de inexistir uma definição unânime sobre a temática, é possível compreender big data como um conjunto de dados multivariados coletados em tempo real dos usuários da internet, que são armazenados pelos controladores, com o objetivo de receber o tratamento adequado e extrair informações úteis, em tempo recorde e com certa veracidade. Ele é capaz de demonstrar as estatísticas e a correlação entre os dados. Já as tecnologias baseadas em Inteligência Artificial são capazes de garimpar informações confiáveis na mesma velocidade do crescimento exponencial da quantidade de dados criados. Andrew Ferguson revela que as sociedades empresárias oferecem inúmeros serviços, informações e comodidade, exigindo como moeda de troca os dados pessoais dos usuários, a nova moeda do mundo moderno (FERGUNSON, 2017).
} 
A regulação do agir decisório disruptivo no judiciário brasileiro e a observância do princípio da precaução: juiz natural ou "juiz artificial"?

sociedade caminha para a "Quarta Revolução Industrial", pois "estamos à beira de uma revolução tecnológica que alterará fundamentalmente a maneira como vivemos, trabalhamos e nos relacionamos." Para o autor, algumas tecnologias específicas fazem parte dessa revolução. São elas a Internet das Coisas (IoT), robótica avançada, os novos materiais manufaturados com as nanotecnologias, os dispositivos autônomos e a Inteligência Artificial.

Por sua vez, existem riscos incertos da IA no tratamento de dados, em qualquer dos campos mencionados acima. Tais riscos podem ser observados em três pontos específicos, acerca:

a) da imprevisibilidade dos algoritmos preditivos que tomam decisões autônomas (ERNST, 2020, p. 57);

b) das vulnerabilidades significativas de segurança, diante de ataques cibernéticos e do uso indevido de dados pessoais por sociedades empresárias e pelo Estado, principalmente pelo Poder Judiciário (TURNER, 2019, p. 275) e;

c) das tendências de concentração de mercado no setor privado, o que pode impactar os escritórios de advocacia.

Mais do que isso, o crescimento da IA revela preocupações jurídicas acerca da segurança, saúde, liberdade, privacidade, dignidade e autodeterminação da pessoa humana. Ela trabalha com uma grande quantidade de dados que, muitas das vezes, traduzem-se em dados sensíveis sobre "[...] origem racial ou étnica, convicção religiosa, opinião política, filiação a sindicato ou a organização de caráter religioso, filosófico ou político, dado referente à saúde ou à vida sexual, dado genético ou biométrico [...]." (BRASIL, 2018, online). O processamento desses dados por agentes públicos e privados pode gerar problemas sociais e éticos, que envolvem a estigmatização de estereótipos, a segregação e a exclusão social, a discriminação e a vigilância (LEMOS, 2020). Podem, ainda, revelar riscos à democracia, por meio da disseminação de fake news e de campanhas eleitorais personalizadas com base na perfilização estratégica de eleitores, bem como a violação de normas processuais, quando se prevê a adoção de algoritmos decisores protegidos pelo segredo industrial, que serão empregados no julgamento de demandas judiciais (CURRAN, 2018). Diante dessas incertezas, a IA está sendo alvo de tentativas regulatórias setoriais, que não propõem, até o momento, um marco regulatório amplo sobre a temática.

\section{A LGPD COMO ESTRATÉGIA REGULATÓRIA DA INTELIGÊNCIA ARTIFICIAL}

Diante das incertezas técnicas, científicas, sociais e econômicas da Inteligência Artificial, novos diplomas nacionais e regionais sobre proteção de dados pessoais 
começam a surgir. Até o momento, foram adotadas leis domésticas específicas sobre a temática em 132 (centro e trinta e dois) países (GREENLEAF, 2019). O principal motivo do esforço regulatório, além do anseio pela tutela da privacidade dos cidadãos, está na abordagem comum da União Europeia sobre o tema, com a adoção do Regulamento (UE) 679/2016, denominado de Regulamento Geral de Proteção de Dados (RGPD), em substituição à Diretiva 95/46/CE.

Seguindo a tendência mundial, o Brasil incorporou no seu ordenamento jurídico a Lei n. 13.709, de agosto de 2018, que convencionou chamar de Lei Geral de Proteção e Dados Pessoais (LGPD). ${ }^{4}$ Inspirada nos avanços legislativos europeus, a Lei institui um microssistema que passará a vigorar na sua integralidade a partir de agosto de 2020.

Para além da proteção da privacidade, ${ }^{5}$ a LGPD prevê um rol de fundamentos, objetivos e princípios específicos, que abarcam a proteção da autodeterminação informativa, da igualdade, da liberdade de expressão, dos direitos humanos, da dignidade e da cidadania dos titulares dos dados pessoais. O legislador ressaltou, ainda, a importância de entrelaçar a proteção dos usuários finais com a necessidade de manutenção do desenvolvimento tecnológico e da inovação, bem como da livre iniciativa e da livre concorrência no mercado de dados. É importante ressaltar que a LGPD também é aplicável às pessoas jurídicas de direito público, entre elas o Judiciário.

É possível observar múltiplas tendências europeias na LGPD brasileira, que prevê a formação de uma gestão de dados pessoais, por meio do estabelecimento de um arranjo jurídico-institucional dedicado à governança dos riscos. A Lei visa a estabelecer mecanismos jurídicos e técnicos voltados à proteção dos usuários. Cria-se, também, uma espécie de cooperação entre agentes públicos e privados para a compreensão e o acompanhamento do desenrolar tecnológico. Isso pode ser notado por meio da previsão de dois temas: (i) a previsão do Capítulo VII (arts. 46 ao 51), dedicado à segurança e boas práticas no manejo dos dados; e (ii) a criação da Agência Nacional de Proteção de Dados (ANPD) e do Conselho Nacional de Proteção de dados pessoais e da privacidade, que regulamentará o setor (Capítulo IX, arts. 55 ao 59).

Cabe mencionar ainda que, durante os 28 (vinte e oito) anos de existência comercial da Word Wide Web, houve um crescimento exponencial e mundial de sociedades empresárias multinacionais que autorregularam essa "black box" (PASQUALE, 2015). Nesse período, as tecnologias de coleta, armazenamento,

\footnotetext{
${ }^{4}$ Cabe mencionar que, no Brasil, algumas iniciativas setoriais relativas à proteção de dados pessoais já haviam ocorrido com as Leis: a) Lei n 12.965/2014 (Marco Civil da Internet); b) Lei 12.414/2011, com alterações da Lei Complementar n. 166/2019 (Lei do Cadastro Positivo); e c) Lei n. 8.078/1990 (Código de Defesa do Consumidor).

${ }^{5} \mathrm{Um}$ dos marcos iniciais dos estudos sobre um direito à privacidade no mundo ocidental está em Warren e Brandeis (1890). Por outro lado, as concepções modernas de privacidade podem ser observadas, por exemplo, em Rodotá (2008). Esse autor defende a existência do direito à proteção de dados como um direito fundamental autônomo.
} 
A regulação do agir decisório disruptivo no judiciário brasileiro e a observância do princípio da precaução: juiz natural ou "juiz artificial"?

processamento e tratamento de dados pessoais evoluíram e tornaram possível a criação de perfis detalhados dos usuários. Todas as buscas on-line, as mensagens e os e-mails recebidos, os textos lidos, produtos e serviços adquiridos, entre outros itens, são registrados instantaneamente pelos provedores (ONU, 2016, p. 4). A base jurídica consistia, até pouco tempo, apenas em um contrato de adesão eletrônico, item que permitia a vigilância - quase que irrestrita - dos rastros digitais deixados pelos usuários (MITTS, 2014, p. 3). Assim, todos esses dados pessoais que, antes das leis de específicas de proteção, careciam de um marco regulatório específico, se viram diante de uma outra problemática: a regulação das ferramentas tecnológicas empregadas nesse meio.

$\mathrm{Na}$ LGPD, não existem disposições expressas que mencionem a Inteligência Artificial. Contudo, a Lei tangencia a temática quando aborda a necessidade de desenvolvimento de ferramentas seguras para o tratamento de dados pessoais. $\mathrm{O}$ art. 46 preleciona que "Os agentes de tratamento devem adotar medidas de segurança, técnicas e administrativas aptas a proteger os dados pessoais de acessos não autorizados e de situações acidentais ou ilícitas de destruição, perda, alteração, comunicação ou qualquer forma de tratamento inadequado ou ilícito." (BRASIL, 2018, online). Em seguida, o art. 47 informa que "Os agentes de tratamento ou qualquer outra pessoa que intervenha em uma das fases do tratamento obriga-se a garantir a segurança da informação prevista nesta Lei em relação aos dados pessoais, mesmo após o seu término.” (BRASIL, 2018, online). O paradigma do privacy by design também é abordado, nos termos do art. 48 "Os sistemas utilizados para o tratamento de dados pessoais devem ser estruturados de forma a atender aos requisitos de segurança, aos padrões de boas práticas e de governança e aos princípios gerais previstos nesta Lei e às demais normas regulamentares." (BRASIL, 2018, online). Em acréscimo, o parágrafo primeiro do art. 50 ressalta que: "Ao estabelecer regras de boas práticas, o controlador e o operador levarão em consideração, em relação ao tratamento e aos dados, a natureza, o escopo, a finalidade e a probabilidade e a gravidade dos riscos e dos benefícios decorrentes de tratamento de dados do titular." (BRASIL, 2018, online).

O principal desafio para a ciência jurídica está em colaborar com a regulação da IA, que possui implementação simultânea ao seu desenvolvimento. Tal atividade está cercada de dificuldades presentes no crescente descompasso entre a inovação e a regulação estatal. Trata-se, portanto, de um "problema de ritmo" entre a capacidade disruptiva das novas tecnologias e a problemática da adoção de estruturas regulatórias fundadas em uma "base factual incerta e politizada." (FENWICK; KAAL; VERMEULEN, 2017). Até o momento, inexistem regulamentos amplos sobre Inteligência Artificial no Brasil ou no exterior. O desenrolar dessa tecnologia se dá por meio de documentos sem força cogente adotados por organizações internacionais e agentes privados. Essa tecnologia emerge de diferentes estudos, manuais e guias elaborados por distintos atores públicos e privados. 
Diante desse cenário incerto, as leis sobre a proteção de dados pessoais estão buscando incentivar e implementar modelos de governança no desenvolvimento de tecnologias baseadas na Inteligência Artificial, com o objetivo de evitar riscos que podem ser minimizados com base no privacy by design. Foi o que ocorreu com os regulamentos implementados na União Europeia e em diversos países, tal como o Brasil, que preveem a possibilidade de antecipação das ações voltadas à prevenção de danos e responsabilização proativa dos desenvolvedores e dos fornecedores das novas tecnologias (FRAZÃO, 2019, p. 481).

Sobre as discussões regulatórias regionais da IA, é interessante mencionar que a União Europeia, importante centro de desenvolvimento dessa tecnologia, adotou uma Declaração de Cooperação sobre o tema em 2018, que foi endossada por 25 Estadosmembros. O documento cria uma rede de cooperação técnica e regulatória em IA. Em 2019, o Parlamento Europeu emitiu a Resolução (2018/2088 (INI)), sobre uma política industrial europeia completa no domínio da Inteligência Artificial e robótica. No item 19 do documento, o Parlamento entendeu que os avanços dessa tecnologia devem ser conduzidos com base no princípio da precaução. Posicionamento reforçado no item 125, em que se afirmou afirmou a necessidade de garantir "[...] um nível elevado de proteção, segurança e privacidade dos dados usados na comunicação entre pessoas, robôs e Inteligência Artificial.” (UNIÃO EUROPEIA, 2019). Em acréscimo, a Comissão Europeia adotou o Comunicado $\operatorname{COM}(2018) 237$, sobre "A Inteligência Artificial para a Europa", relatando que existem trabalhos para a atualização regulatória setorial da Inteligência Artificial, visando a minimizar a insegurança no seu desenvolvimento. Além disso, a Comissão entendeu que o RGPD fornece um nível elevado de proteção aos dados pessoais que estão sujeitos à IA. (UNIÃO EUROPEIA, 2018, parágrafos 19 e 125).

$\mathrm{Na}$ iniciativa privada, tais avanços regulatórios são vistos com receio por algumas organizações. Entre elas, a Information Technology $\mathcal{E}$ Innovation Foundation (ITIF) discorda da implementação de marcos regulatórios em IA, mesmo que setoriais, tais como as legislações de proteção de dados pessoais (WALLACE; CASTRO, 2018). A ITIF, que é sediada nos Estados Unidos da América, entende que esse cenário gera desvantagens competitivas entre sociedades empresárias de diferentes regiões do planeta. Na disputa pela liderança da IA, os países que regulam a proteção de dados pessoais estariam gerando custos excessivos à iniciativa privada e se distanciando da competição mundial, que tende a permanecer entre China e EUA. Além disso, a ITIF entende que a adoção do princípio da precaução nessa seara prejudicará o crescimento econômico e o progresso tecnológico (CASTRO; MCLAUGHLIN, 2019). Por outro lado, Elon Musk, diretor executivo de grandes sociedades empresárias de tecnologia, defende a regulação imediata da Inteligência Artificial, mesmo que por meio de diplomas específicos (tal 
A regulação do agir decisório disruptivo no judiciário brasileiro e a observância do princípio da precaução: juiz natural ou "juiz artificial"?

como a LGPD), pois ela representaria potenciais riscos à humanidade (TURNER, 2019, p. 166).

Portanto, é possível afirmar que existem divergências sobre a regulação da Inteligência Artificial, temática que exige maior atenção dos pesquisadores. $O$ presente artigo científico, contudo, ressalta a importância das leis setoriais de proteção de dados como marcos regulatórios centrais ao desenvolvimento da IA nos setores público e privado. Nesse ponto, o próximo tópico ressaltará que o Poder Judiciário está atento às inovações propostas pela IA, não apenas como o objeto das lides, mas também como instrumento tecnológico capaz de fornecer uma "nova arquitetura" ao próprio Direito e aos tribunais.

\section{O RECORTE SETORIAL: A APLICAÇÃO DA INTELIGÊNCIA ARTIFICIAL NO PODER JUDICIÁRIO}

A International Business Machines (IBM) afirma que diferentes áreas do Direito estão recebendo os avanços da IA. Na advocacia, já existe a possibilidade de: (i) prever o resultado do litígio com mais precisão; (ii) otimizar o tempo dos advogados com a utilização de softwares que emitem relatórios e minutas em poucos segundos; (iii) receber resumos com as principais estratégias para solução dos casos, com a indicação da solução mais eficiente; (iv) analisar o comportamento individualizado de cada magistrado, com base no seu histórico de decisões; e (v) calcular automaticamente os honorários devidos (ARTIFICIAL..., 2018). Essa nova visão, entretanto, exige dos juristas uma formação jurídica que é híbrida com as novas ferramentas tecnológicas, bem como uma capacitação focada na dinamicidade desse novo cenário laboral (FEFERBAUM; LIMA, 2020). Além dos advogados, os tribunais também estão começando a empregar tais inovações, principalmente com programas de computador capazes de minerar processos em busca de dados específicos para organizá-los e facilitar o fluxo de informações. Algumas dessas tecnologias já fornecem mecanismos decisórios autônomos, capazes de resolver demandas repetitivas ou fornecer o padrão de comportamento e os antecedentes criminais de agentes demandados em processos criminais. $O$ sistema de precedentes tem muito a ganhar com essa nova tecnologia, conforme aponta a pesquisa de Sabo e Rover (2020, p. 81).

O avanço da IA no Judiciário brasileiro já ultrapassa o mero recebimento, categorização e triagem de processos on-line. Trata-se de uma inovação que vai além dos sistemas destinados à automação. Entre tais sistemas, destacaram-se no cenário nacional o Sistema de Automação do Judiciário (SAJ), o "e-Proc" do Tribunal Regional Federal da Quarta Região, o Processo Judicial Eletrônico (Pje) do Conselho Nacional de Justiça (CNJ) e o Processo Judicial Eletrônico (Projudi). Atualmente, o Judiciário busca soluções tecnológicas que sejam capazes de otimizar a própria tarefa decisória dos magistrados, ou 
seja, a criação e o emprego de robôs (softwares) na solução de casos concretos, com base no aprendizado de máquina (machine learning).

Nesse ponto, é interessante notar que os tribunais recebem esses avanços por meio da colaboração das equipes de Tecnologia da Informação dos tribunais, da contratação de agentes privados ou da parceria com laboratórios públicos financiados. $\mathrm{O}$ desenvolvimento de novos programas de IA no setor público brasileiro encontra dificuldade e atrasos diante da aplicação dos pressupostos clássicos licitatórios da Lei n. 8.666/93, o que acaba dificultando a contratação de profissionais e empresas capacitadas para tanto (PRESIDENTE..., 2019). Diante desse cenário, alguns tribunais brasileiros buscaram alternativas para implementar a IA. Entre eles, o Supremo Tribunal Federal (STF) firmou um termo de execução descentralizado com a Universidade de Brasília (UNB) para o desenvolvimento e a implementação da Inteligência Artificial denominada de "Victor".

Ao custo de 1,6 milhão de reais, "Victor" é um programa de computador (software) que auxilia os ministros do STF a interpretar as informações contidas nos processos, separar os recursos por temas, destacar trechos de peças processuais, bem como agilizar o trâmite de demandas e tornar as informações mais fluídas entre os gabinetes. Contudo, a grande aposta nessa IA está em uma nova funcionalidade que permite a resolução autônoma de 1/8 (um oitavo) dos Recursos Extraordinários (REs) em trâmite. Isso ocorre porque o programa tem capacidade de identificar as demandas que chegam à Corte, realizar a triagem e devolver o processo para as instâncias inferiores quando a matéria já tenha sido objeto de Repercussão Geral. Caso as partes discordem do resultado obtido pela máquina, podem utilizar os meios recursais tradicionais para que a demanda seja reavaliada. Além disso, para resolver o problema de processos antigos e escaneados, Victor tem a capacidade de interpretar imagens e transformá-las automaticamente em texto, com a tecnologia denominada de Optical Character Recognition (OCR) (TEIXEIRA, 2018).

O Superior Tribunal de Justiça (STJ) também trabalha com dois sistemas semelhantes denominados de "Projeto Sócrates" e "Athos", que estão em constante aperfeiçoamento pela Assessoria de Inteligência Artificial do Tribunal. Ainda em testagem, o objetivo principal é que os Programas auxiliem no julgamento de processos repetitivos, na emissão automática de relatórios (com a menção da legislação e da jurisprudência correlatas) e na criação de uma minuta do próprio acórdão (BATITUCCI; MARTINS, 2019). Os Programas também têm a capacidade de barrar as demandas que o STJ seja incompetente para julgar. O "treinamento" da IA do STJ se deu com base em mais de trezentas mil decisões pertencentes ao acervo do próprio Tribunal. Em 2020, a versão "Sócrates 2" pretende expandir a aplicação do software e possibilitar que os ministros recebam as demandas com um relatório completo de cada uma, prescindindo de qualquer intervenção humana (FERREIRA, 2020). 
A regulação do agir decisório disruptivo no judiciário brasileiro e a observância do princípio da precaução: juiz natural ou "juiz artificial"?

O Tribunal Superior do Trabalho (TST) também busca constantemente por inovações. O sistema inteligente "Bem-te-Vi" está em utilização desde 2008 e foi desenvolvido como ferramenta auxiliar dos servidores na análise da tempestividade dos processos trabalhistas em trâmite na Corte. É interessante pontuar que o software desenvolvido pelo setor de TI do TST consegue integrar informações de diferentes sistemas de automação já existentes e economizar recursos humanos em atividades de fácil execução. Há projetos em andamento que pretendem aperfeiçoar as atividades desenvolvidas pelo sistema (INTELIGÊNCIA..., 2020).

Instâncias inferiores também estão na corrida pelo desenvolvimento de novas ferramentas inteligentes. Atualmente, o Projeto em destaque é a IA “Elis”, desenvolvida pela Direção de Tecnologia da Informação do Tribunal de Justiça de Pernambuco (TJPE). O sistema faz uma análise completa das ações de execução fiscal, decidindo quais estão prescritas e quais observam adequadamente as regras processuais para, então, indicar a decisão tomada, inclusive entregando ao juiz o texto pronto da decisão. $\mathrm{O}$ único trabalho do magistrado é assinar eletronicamente a decisão da Elis, que indica ao final do texto que se trata de uma decisão construída pela máquina. O TJPE desenvolveu um sistema de IA sem custos adicionais aos cofres públicos, já que foi desenvolvida pelos próprios servidores especializados do TJPE. Outro ponto está na transparência promovida pelo Tribunal, quando informa as partes sobre a decisão autônoma e possibilita que ataquem esse ponto específico da utilização de novas tecnologias no agir decisório do magistrado (FERREIRA, 2020).

Por outro lado, a principal problemática na adoção massiva dessa tecnologia nas atividades finalísticas do Poder Judiciário está no seu funcionamento baseado em algoritmos e informações que estão fora do alcance cognitivo dos juristas dos diferentes ramos jurídicos. Atualmente, grande parte da IA aplicada ao Judiciário é baseada em modelos que seguem regras preestabelecidas e respeitam inteiramente a sequência criada. Trata-se de uma versão Narrow AI. Contudo, já se pensa no desenvolvimento de mecanismos de redes neurais que dão a capacidade de a IA ultrapassar esses comandos humanos e possibilitam que a máquina crie outras conexões criativas e completamente artificiais. Trata-se, como visto na seção 2, do denominado aprendizado de máquina, campo pertencente à General AI.

Conforme ressalta Scherer (2019, p. 22-24), a aplicação da IA no Judiciário pode ser denominado de "a caixa-preta da tomada de decisões judiciais" pois, até mesmo, pesquisadores qualificados afirmam que, em alguns casos, não é possível identificar a lógica utilizada pela máquina para alcançar determinado resultado. Para os juristas, a complicação é ainda maior, pois a máquina ainda não é capaz de fornecer uma fundamentação jurídica para a decisão autônoma. Justamente para contornar tal dificuldade, que pode repelir a aplicação da IA no Judiciário, foram criados programas que visam a desenvolver inteligências artificiais que sejam explicáveis e desenhadas 
conforme as Leis de proteção de dados pessoais. Entre tais programas, cita-se o U.S. Explainable Artificial Intelligence (XAI) Program (TUREK, 2020).

Além disso, a IA no Judiciário precisa enfrentar outra temática importante sobre a propriedade industrial, principalmente no que tange ao segredo industrial das empresas que desenvolvem tal tecnologia. A temática já gera divergências no judiciário norte-americano nas demandas criminais, tendo em vista que há uma alta automação dos procedimentos de policiamento, investigação, encarceramento preventivo, análise de evidências (DNA, impressões digitais e faciais e balística) e de antecedentes criminais. Cada vez mais, os EUA utilizam softwares inteligentes para orientar e fornecer dados às sentenças criminais. Para Wexler (2018), essa automação pode gerar a privatização maciça dos sistemas de justiça, já que a propriedade sobre os programas inteligentes pertence aos agentes privados e não ao Estado.

Nesse passo, alguns tribunais norte-americanos já decidiram acerca da temática da tensão entre propriedade intelectual e garantias processuais na utilização da IA dentro do Poder Judiciário. Na Pensilvânia, a State Court negou ao investigado o acesso aos algoritmos utilizados pelo software que o identificou como o autor de um crime, por meio de um sistema de análise de provas (ESTADOS UNIDOS DA AMÉRICA, 2016). A Federal Court do Texas entendeu que o segredo industrial deve preponderar sobre o direito dos investigados de obterem informações necessárias para garantir o exercício direito de defesa (ESTADOS UNIDOS DA AMÉRICA, 2013). Em Wisconsin, a State Supreme Court manteve a mesma linha argumentativa, acrescentando que tanto o magistrado quanto o réu tinham acesso limitado à IA e que, por esse motivo, nenhum deles poderia quebrar o sigilo do software para rever a condenação (ESTADOS UNIDOS DA AMÉRICA, 2016).

Por outro lado, em decisão inédita que busca conter o avanço da IA nas carreiras jurídicas, a França decidiu proibir e criminalizar a utilização de Inteligência Artificial por pessoas que criarem perfis sobre o agir decisório dos juízes. Trata-se de um comportamento isolado no mundo ocidental. A Lei francesa $n^{\circ} 2019-222$ du 23 mars 2019 de programmation 2018-2022 et de réforme pour la justice dispõe no seu art. 33 que: "Os dados de identidade dos magistrados e membros do judiciário não podem ser reutilizados com o objetivo ou efeito de avaliar, analisar, comparar ou prever suas práticas profissionais reais ou alegadas [tradução não oficial]”. ${ }^{6}$ A punição máxima estabelecida na Lei consiste na prisão do infrator por até cinco anos (FRANÇA, 2019).

\footnotetext{
${ }^{6}$ Trecho original do art. 3o da supramencionada Lei francesa: "Les données d'identité des magistrats et des membres du greffe ne peuvent faire l'objet d'une réutilisation ayant pour objet ou pour effet d'évaluer, d'analyser, de comparer ou de prédire leurs pratiques professionnelles réelles ou supposées. La violation de cette interdiction est punie des peines prévues aux articles 226-18,226-24 et 226-31 du code pénal, sans préjudice des mesures et sanctions prévues par la loi n 78-17 du 6 janvier 1978 relative à l'informatique, aux fichiers et aux libertés." (FRANÇA, 2019).
} 
A regulação do agir decisório disruptivo no judiciário brasileiro e a observância do princípio da precaução: juiz natural ou "juiz artificial"?

Não existem dados sobre a aplicação desse dispositivo francês em casos concretos. Contudo, parece que o legislador procurou evitar que dados públicos fossem sistematizados, disponibilizados em bancos de jurisprudência e utilizados por profissionais ou, até mesmo, por cidadãos. A iniciativa europeia denominada de Artificial Lawyer entende que o dispositivo viola frontalmente o direito à informação dos cidadãos, pois impede que tenham acesso facilitado às decisões dos magistrados franceses e que gerem novos conhecimentos a partir da análise de dados que são públicos (FRANCE..., 2019).

No Brasil, os tribunais e os advogados ainda têm o poder de desenvolver tecnologias baseadas em IA e de decidir quando devem confiar nela. Essa confiança é gerada por meio do cumprimento bem-sucedido de tarefas delegadas às máquinas, mesmo que se desconheça a logística do seu funcionamento. A ampliação da IA no Poder Judiciário ou a sua abolição depende dos próximos passos a serem dados pelos desenvolvedores dessa tecnologia, bem como dos debates públicos sobre a legitimidade do agir decisório baseado em algoritmos.

Em uma visão otimista, alguns autores defendem que a IA alterará a arquitetura de todo o Direito, fazendo que as leis percam importância e cedam lugar para os padrões racionais baseados em algoritmos. Por sua vez, esses algoritmos serviriam como base para a geração de sentenças e acórdãos por meio de softwares e não de juízes. Assim, a regulação da conduta humana não seria mais pautada pela Ciência Jurídica em si, mas pela Ciência da Computação (FAGAN; LEVMORE, 2019, p. 15).

O próximo tópico se ocupará com a temática da união do desenvolvimento tecnológico com os pressupostos sustentáveis abordados pelo princípio da precaução.

\section{O PANORAMA "PRECAUCIONAL" NO DESENVOLVIMENTO DE ROBÔS DECISORES}

Conforme delineado por Ulrich Beck, os avanços científicos e tecnológicos conduziram a humanidade a uma "sociedade de risco". A intensificação das mudanças científicas e tecnológicas produzidas pelos seres humanos geraram reflexões éticas, sociais e políticas sobre a atual fase vivenciada pela modernidade. Essa fase representada pela "deslocalização", pela "incalculabilidade" e pela "não compensabilidade" dos riscos busca ponderar o sucesso do progresso industrial e as consequências negativas perpetradas na sociedade (BECK, 1998, p. 54). Hermitte (2005, p. 319) afirma que "não se trata mais de prevenir os riscos tecnicamente e de indenizá-los, é preciso decidir de forma democrática e assegurar uma distribuição justa."

Segundo Noiville (2004, p. 319) o “"ponto de equilíbrio' desse cenário de produção de riscos em sociedade está na interseção entre os princípios da prevenção e da precaução, medidas que antecedem o dano e são baseadas no 'risco provado' ou no 
'risco potencial.” Nesse passo, Teresa Ancona Lopez afirma que o princípio possui natureza jurídica de princípio jurídico, composto por "diretrizes normativas" voltadas a evitar possíveis danos. Dentro desse princípio, haveria standards de precaução, que apresentam requisitos de apreciação dos riscos potenciais com base no conhecimento científico, político, econômico, sociológico, ético e estatístico já consolidados. Esses standards se utilizam dos critérios da razoabilidade e da proporcionalidade (LOPEZ, 2010, p. 95).

Os fundamentos filosóficos desses princípios estão nos estudos de Hans Jonas sobre "o princípio da responsabilidade: ensaio de uma ética para a civilização tecnológica", realizados na década de 1970. Jonas explica que a tecnologia modificou a relação do homem com a natureza. Ele passou a controlá-la pela "técnica", mas sem compreender todos os efeitos maléficos. Esse novo cenário exige a adoção de uma "responsabilidade humana”, que não possui relação com a responsabilidade jurídica, mas com o desenvolvimento de uma nova ética pautada na responsabilidade por antecipação, para proteger e preservar os recursos naturais e a qualidade de vida das gerações futuras. Para Philippe Kourilsky e Geneviève Viney, esse raciocínio parte da ação baseada na "prudência", o "fio condutor" dos princípios da prevenção e da precaução, mas com ela não se confunde porque eles vão além da prudência convencional utilizada no cotidiano das pessoas (KOURILSKY; VINEY, 1999, p. 11).

É importante ressaltar que não existem definições universalmente aceitas sobre o princípio da precaução. Entretanto, é possível extrair observações semelhantes e coincidentes realizadas pela literatura jurídica. $O$ ponto principal está na distinção entre a prevenção e a precaução. $O$ primeiro pode ser delimitado na possibilidade de adoção de medidas de proteção que visam a diminuir os riscos conhecidos e comprovados pela ciência, como forma de gerenciar perigos e evitar danos ao meio ambiente e/ou à saúde humana (BOURGUIGNON, 2015, p. 3). Por outro lado, a precaução consiste em um alargamento da noção de prevenção, para viabilizar medidas preventivas quando os riscos ainda são incertos ou hipotéticos e os conhecimentos científicos ainda são incipientes. Trata-se de uma "antecipação" dos eventuais danos que determinada atividade, produto ou serviço possa causar na seara ambiental, social, laboral e consumerista (LOPEZ, 2010, p. 103). Enquanto o princípio da prevenção é “reativo”, o princípio da precaução é "proativo” (ARAGÃO, 2008, p. 19).

Segundo Sands (2004), as discussões sobre o princípio da precaução são recentes, pois atribui-se a sua origem ao direito alemão da década de 1970, principalmente com as pesquisas de Rehbinder e Winter (2004, p. 29). Cabe mencionar, também, que tal princípio foi amplamente discutido no nível internacional. Em um primeiro momento, as discussões centraram-se em temáticas ambientais. Um importante ato para a consolidação principiológica da precaução foi assentado na Declaração de Wingspread em 1998 (OMC, 1998). 
A regulação do agir decisório disruptivo no judiciário brasileiro e a observância do princípio da precaução: juiz natural ou "juiz artificial"?

O princípio da precaução também foi absorvido pelo nível regional no Direito da União Europeia, por meio da previsão inicial no Tratado de Maastrich em 1992, e posteriormente na Comunicação de 2000, da Comissão Europeia, relativa ao princípio da precaução (ARAGÃO, 2008, p. 10). Nessa oportunidade, a Comissão explicitou que o princípio da precaução apenas deve ser aplicado quando "[...] a informação científica for incompleta, inconclusiva ou incerta e onde há indícios de que os possíveis efeitos sobre o meio ambiente ou a saúde humana, animal ou vegetal poderiam ser perigosos e inconsistentes com o nível escolhido de proteção." (UNIÃO EUROPEIA, 2000).

Essa expansão do princípio da precaução em diferentes níveis e para além das questões ambientais se deu em razão de eventos que afetaram diretamente outros bens jurídicos igualmente importantes, relacionados à incolumidade física e à saúde da pessoa humana. Kourilsky e Viney (1999, p. 13) afirmam que, além do surgimento de novos riscos, a ampliação da esfera de aplicação do princípio da precaução se deu com o fracasso das políticas e instrumentos preventivos.

No cenário nacional brasileiro, há previsão expressa do princípio da precaução apenas na Lei n. 11.105/2005 (Lei de Biossegurança), logo no primeiro dispositivo. Contudo, nota-se a aplicação do princípio de maneira implícita em alguns diplomas infraconstitucionais e também em decisões judiciais. Recentemente, o Supremo Tribunal Federal (STF), em julgado "sobre campos eletromagnéticos de linhas de transmissão de energia", firmou-se uma Tese em Repercussão Geral, com base no princípio da precaução. O Ministro Relator expôs um conceito específico para o princípio, afirmando que se trata de "[...] um critério de gestão de risco a ser aplicado sempre que existirem incertezas científicas sobre a possibilidade de um produto, evento ou serviço desequilibrar o meio ambiente ou atingir a saúde dos cidadãos [...]." (BRASIL, 2016, online).

Entretanto, alguns autores entendem que tal princípio não oferece a melhor solução para contornar ou evitar as mazelas da "sociedade de risco". Nesse passo, as principais críticas ao princípio da precaução concentram-se em três argumentos centrais, que o consideram:

a) "retrógrado" (BAILEY, 1999; MAJONE, 2002);

b) "anticientífico" (MARCHANT; MOSSMAN, 2004) e;

c) "paralisante" (SUNSTEIN, 2005). Parte dessa literatura jurídica dissidente apresenta outras alternativas principiológicas, tais como a adoção do "princípio da resiliência" (principle of resilience), do "princípio da novidade" (principle of novelty) e do "princípio da inovação" (innovation principle).

Toda essa carga histórica, doutrinária e prática do princípio da precaução, para além das divergências apontadas acima, podem servir como "fio condutor" da temática da Inteligência Artificial aplicada no Poder Judiciário. Nesse sentido, entende-se que o 
princípio indica dois caminhos - não excludentes - para o desenvolvimento seguro da IA, quais sejam, a governança e a regulação (em sentido lato).

Rhodes considera o termo "governança” polissêmico, sendo aplicável em diferentes áreas, como nas políticas públicas, no setor empresarial (governança corporativa) e nas relações internacionais. Segundo o autor, a definição abrange o funcionamento de "redes auto-organizadas e interorganizadas" destinadas a complementar as necessidades dos mercados, devido aos limites presentes no ato de "governar sozinho", pois, nesses cenários, requer-se a negociação e a cooperação de diversos atores sociais (RHODES, 1996). Nesse passo, o papel da governança na gestão dos riscos gerados pelas novas tecnologias consiste em um processo de ampliação do poder decisório e negocial, que ultrapassa a figura estatal. Abarca-se nessa visão, portanto, a participação ativa dos atores, para harmonizar as divergências científicas e encontrar um "ponto comum" no desenvolvimento científico. Didier Bourguignon, em relatório elaborado para o Parlamento Europeu, explica que a "governança dos riscos" possui componentes técnicos essenciais para o seu sucesso (BOURGUIGNON, 2015, p. 22).

Por outro lado, a "regulação" consiste em um termo multidisciplinar que pode ser aplicado em uma ampla gama de áreas, sendo que inexiste uma definição unânime para o Direito. Contudo, é possível observar três elementos centrais na sua caracterização no estudo de Baldwin, Cave e Lodge (2012, p. 2). A primeira característica revela que ela perfaz um "conjunto específico de comandos que envolve a promulgação de um conglomerado de regras vinculativas a serem aplicadas por um órgão estatal dedicado a essa finalidade [tradução nossa].” A segunda característica demonstra que a regulação abarca a "influência deliberada do Estado, onde regulação tem um sentido mais amplo e abrange todas as ações estatais que são projetadas para influenciar os negócios ou o comportamento social [tradução nossa]”. A terceira característica revela uma ampliação do conceito de regulação, o qual desponta "toda forma de influência social e/ou econômica, em que todos os mecanismos que afetam o comportamento - estatais ou de outras fontes - são considerados regulação [tradução nossa].” (BALDWIN; CAVE; LODGE, 2012, p. 3). Nesse último ponto, os autores acrescentam que a teoria da smart regulation admite outras formas de regulação não jurídicas elaboradas e geridas "fora" do Estado, tais como a autorregulação de sociedades empresárias e de corporações profissionais e a corregulação (BALDWIN; CAVE; LODGE, 2012, p. 4). ${ }^{7}$ É possível encaixar nesse rol, ainda, a regulação das organizações internacionais e de organizações não governamentais de normalização.

\footnotetext{
${ }^{7}$ Trechos no original: "As a specific set of commands-where regulation involves the promulgation of a binding set of rules to be applied by a body devoted to this purpose [...] As deliberate state influencewhere regulation has a more broad sense and covers all state actions that are designed to influence business or social behavior. [...] As all forms of social or economic influence-where all mechanisms
} 
A regulação do agir decisório disruptivo no judiciário brasileiro e a observância do princípio da precaução: juiz natural ou "juiz artificial"?

Por fim, a observância do princípio da precaução no setor dos tribunais pode servir como base na formulação e na implementação de políticas públicas, visando a otimizar o desenvolvimento tecnológico baseado no privacy by design, capaz de reduzir as incertezas científicas, remover as imperfeições e os riscos nos processos de tomada de decisões dos robôs decisores e solidificar a prudência no tratamento de dados, principalmente na proteção da privacidade, saúde e segurança dos jurisdicionados.

Não se desconhece, contudo, que a aplicação do princípio da precaução nesses casos depende da interpretação a ser dada pelos próprios magistrados. Esses agentes receberão os benefícios da Inteligência Artificial e poderão influir no desenvolvimento tecnológico no seio do Judiciário para promovê-lo ou restringi-lo. Adverte-se, também, que a aplicação desse princípio não significa a abolição da IA na atividade jurisdicional. Trata-se, pelo contrário, de condicionar a utilização dessa nova tecnologia aos pressupostos jurídicos (e metajurídicos) indicadores dos caminhos seguros e sustentáveis a serem observados pelos seus desenvolvedores.

\section{CONCLUSÃO}

O estabelecimento de um marco regulatório à proteção de dados pessoais, por meio da adoção da LGPD, abrange, para além dos direitos do usuário comum, a utilização de ferramentas tecnológicas que privilegiam tais direitos. Apesar de inexistirem disposições específicas sobre a Inteligência Artificial na referida Lei, pode-se afirmar que os agentes públicos e privados responsáveis pelo desenvolvimento e/ou aplicação dessa tecnologia deverão observar os pressupostos para o seu desenvolvimento seguro, que não gere riscos à coletividade. Assim, a tentativa de criação da Agência Nacional de Proteção de Dados (ANPD), em uma espécie de "governança dos dados", parece refletir, ainda que implicitamente, a adoção pelo legislador brasileiro do princípio da precaução no desenvolvimento de novas tecnologias que trabalhem com dados pessoais, como a Inteligência Artificial.

Identificou-se também que não há previsão expressa do princípio da precaução na LGPD. Entretanto, ele pode potencializar (como vetor interpretativo) a interação entre diferentes atores nacionais, regionais e internacionais, em diferentes setores da sociedade (científico, empresarial, social e consumerista), ampliando - e talvez democratizando - a tomada de decisões sobre os riscos que a coletividade está disposta a suportar. O histórico de aplicação desse princípio, em diferentes áreas científicas e tecnológicas, pode indicar os caminhos para o gerenciamento das incertezas da Inteligência Artificial no Judiciário, principalmente nas suas atividades finalísticas. É

affecting behavior-whether these be state-based or from other sources (e.g. markets)-are deemed regulatory." (BALDWIN; CAVE; LODGE, 2012, p. 3).

110 - R. Opin. Jur., Fortaleza, ano 19, n. 30, p.91-117, jan./abr. 2021 
nesse sentido que o princípio da precaução é capaz de funcionar como "princípio orientador”, tanto para a regulação quanto para a governança da IA no setor privado e público, principalmente no Poder Judiciário, recorte setorial abordado neste artigo, uma vez que: a) tal princípio oferece uma experimentação de diferentes estratégias de regulação, a partir da cooperação entre setor público e setor privado; e b) fundamenta a adoção de políticas públicas, que visam a implementar ações antecipatórias diante dos riscos sociais, políticos e tecnológicos.

\section{REFERÊNCIAS}

ARAGÃO, Alexandra. Princípio da precaução: manual de instruções. Revista CEDOUA, Coimbra, n. 2, p. 9-57, 2008.

ARTIFICIAL Intelligence (AI) for the practice of law: $\mathrm{Na}$ introduction. In: ROSS Intelligence. [São Francisco, 8 ago. 2018]. Disponível em: https://blog.rossintelligence.com/post/ai-introduction-law. Acesso em: 7 abr. 2020.

BAILEY, Ronald. Precautionary Tale: the latest environmentalist concept--the Precautionary Principle--seeks to stop innovation before it happens. Very bad idea. 1999. Disponível em: https://reason.com/1999/04/01/precautionary-tale/. Acesso em: 7 abr. 2020.

BALDWIN, Robert; CAVE, Martin; LODGE, Martin. Understanding Regulation: theory, strategy, and practice. 2. ed. New York: Oxford, 2012.

BATITUCCI, Luiz Anísio Vieira; MARTINS, Amilar Domingos Moreira. Sistemas apoiados por Inteligência Artificial: Superior Tribunal de Justiça. Portal Justiça Federal, [Brasília, jun. 2019]. Disponível em: http://www.justicafederal.jus.br/cjf/corregedoriada-justica-federal/centro-de-estudos-judiciarios-1/eventos/eventos-cej/2019/stj-apresent acao-enastic-junho-2019-2.pdf. Acesso em: 7 abr. 2020.

BECK, Ulrich. Sociedade global, sociedade de riscos. Cadernos da Escola do Legislativo, Belo Horizonte, v. 7, n. 4, p. 53-81, jan./jun. 1998.

BECK, Ulrich. A metamorfose do mundo: novos conceitos para uma nova realidade. Tradução de Maria Luiza Borges. Rio de Janeiro: Zahar, 2018.

BOURGUIGNON, Didier. Le principe de précaution: Définitions, applications et gouvernance, analyse approfondie. Bruxelas: União Europeia (EPRS), 2015. Disponível em: http://www.europarl.europa.eu/RegData/etudes/IDAN/2015/573876/EPRS_ID A(2015)573876_FR.pdf. Acesso em: 4 jul. 2019. 
A regulação do agir decisório disruptivo no judiciário brasileiro e a observância do princípio da precaução: juiz natural ou "juiz artificial"?

BRASIL. Lei ${ }^{\circ}$ 13.709, de 14 de agosto de 2018. Lei Geral de Proteção de Dados Pessoais (LGPD). Brasília, DF: Presidência da República, 2018. Disponível em: http://www.planalto.gov.br/ccivil_03/_ato2015-2018/2018/lei/L13709.htm. Acesso em: 4 jul. 2019.

BRASIL. Supremo Tribunal Federal. Recurso Extraordinário: RE 627189 SP. Órgão Julgador Tribunal Pleno. Relator Min. Dias Toffoli. Jus Brasil, 8 de Junho de 2016. Disponível em: https://stf.jusbrasil.com.br/jurisprudencia/772381181/recursoextraordinario-re-627189-sp-sao-paulo\#: : :text=O\%20princ\%C3\%ADpio\%20da\%20 precau\%C3\%A7\%C3\%A30\%20\%C3\%A9,custos\%20das\%20medidas\%20de\%20preve n\%C3\%A7\%C3\%A3o. . Acesso em: 4 jul. 2019.

CASTRO, Daniel; MCLAUGHLIN, Michael. Ten Ways the Precautionary Principle Undermines Progress in Artificial Intelligence. ITIF, Washington, 2019. Disponível em: https://itif.org/publications/2019/02/04/ten-ways-precautionary-principle-underminesprogress-artificial-intelligence. Acesso em: 13 jan. 2020.

COPELAND, Jack. Artificial Intelligence. In: COPELAND, Jack (ed.). The essential Turing: seminal writings in Computing, Logic, Philosophy, Artificial Intelligence, and Artificial Life. Nova York: Oxford, 2004.

CURRAN, Dylan. Are you ready? Here is all the data Facebook and Google have on you. The Guardian, São Francisco, 30 mar. 2018. Disponível em: https://www.theguardian.com/commentisfree/2018/mar/28/all-the-data-facebookgoogle-has-on-you-privacy. Acesso em: 13 jan. 2020.

DIXON, Pam; GELLMAN, Robert. The scoring of America: How secret consumer scores threaten your privacy and your future. Orlando: World Privacy Forum, 2014. Disponivel em: http://www.worldprivacyforum.org/wpcontent/uploads/2014/04/WPF_Scoring_of_America_April2014_fs.pdf. Acesso em: 13 jan. 2020.

DOMO. Data never sleeps 6.0. 2018. Disponível em: https://webassets.domo.com/blog/wp-content/uploads/2018/05/18_domo_data-never-sleeps6verticals.pdf. Acesso em: 13 jan. 2020.

ERNST, Christian. Artificial intelligence and autonomy: self-determination in the age of automated systems. In: WISCHMEYER, Thomas; RADEMACHER, Timo (ed.). Regulating artificial Intelligence. Cham: Springer, 2020. E-book.

ESTADOS UNIDOS DA AMÉRICA. Superior Court of Pennsylvania. Appeal n. 5 WDM 2016, from the Order dated February 4, 2016 refusing to certify for appeal the trial court's discovery Order dated December 7, 2015 at No. CC 20130007777 in the 
Court of Common Pleas of Allegheny County, Pennsylvania, Criminal Division. Disponível em: https://www.cybgen.com/information/newsroom/2016/apr/files /Brf_Response_to_Pet_f_Revw_Robinson_w_Exh.pdf. Acesso em: 7 abr. 2020.

ESTADOS UNIDOS DA AMÉRICA. United States District Court For The Western District Of Texas El Paso Division. EP-11-CR-2728-KC. 2013. Disponível em: https://casetext.com/case/united-states-v-ocasio-3. Acesso em: 7 abr. 2020.

FAGAN, Frank; LEVMORE, Saul. The Impact of Artificial Intelligence On Rules, Standards, And Judicial Discretion. Southern California Law Review, p. 15, 2019. Disponível em: https://papers.ssrn.com/sol3/papers.cfm?abstract_id=3362563. Acesso em: 7 abr. 2020.

FEFERBAUM, Marina; LIMA, Stephanne H. B. Formação jurídica e novas tecnologias: relato de uma aprendizagem experiencial em Direito. Revista Opinião Jurídica, Fortaleza, v. 18, n. 28, p. 145-162, maio/ago. 2020. doi:10.12662/24476641oj.v18i28.p145-162.2020

FENWICK, Mark D.; KAAL, Wulf; VERMEULEN, Erik. Regulation tomorrow: what happens when technology is faster than law? American University Business Law Review. Washington, v. 6, n. 3, p. 562-594, 2017.

FERREIRA, Flávio. Inteligência artificial atua como juiz, muda estratégia de advogado e 'promove' estagiário. Folha de São Paulo, [São Paulo, 10 mar. 2020]. Disponível em: https://www1.folha.uol.com.br/poder/2020/03/inteligencia-artificial-atua-como-juizmuda-estrategia-de-advogado-e-promove-estagiario.shtml?utm_source=whatsapp\&utm_medium=-social\&utm_campaign=compwa. Acesso em: 7 abr. 2020.

FRANÇA. Loi n $^{\circ}$ 2019-222 du 23 mars 2019 de programmation 2018-2022 et de réforme pour la justice (1). Tradução não oficial. Texto integral e original. Disponível em: https://www.legifrance.gouv.fr/eli/loi/2019/3/23/2019-222/jo/article_33. Acesso em: 7 abr. 2020.

FRANCE Bans Judge Analytics, 5 Years In Prison For Rule Breakers. Artificial Lawyer, 4 jun. 2019. Disponível em: https://www.artificiallawyer.com/2019/06/04/france-bansjudge-analytics-5-years-in-prison-for-rule-breakers/. Acesso em: 7 abr. 2020.

FRAZÃO, Ana. Objetivos e alcance da Lei Geral de Proteção de Dados. In: TEPEDINO, Gustavo; FRAZÃO, Ana; OLIVA, Milena Donato (coord.). Lei Geral de Proteção de Dados Pessoais e suas repercussões no Direito Brasileiro. São Paulo: Thomson Reuters, 2019.

GREENLEAF, Graham. Global Tables of Data Privacy Laws and Bills. (6a edição, fevereiro de 2019). Supplement to 157 Privacy Laws $\&$ Business International Report 
A regulação do agir decisório disruptivo no judiciário brasileiro e a observância do princípio da precaução: juiz natural ou "juiz artificial"?

(PLBIR). Sydney, 2019]. Disponível em: https://ssrn.com/abstract=3380794. Acesso em: 11 mar. 2020.

HERMITTE, Marie-Angèle. Os fundamentos jurídicos da Sociedade de risco. In: VARELLA, Marcelo Dias (org.). Governo dos Riscos. Rede Latino-Americana-Européia sobre Governo dos Riscos. Brasília: Eunice de Oliveira, 2005.

INTELIGÊNCIA artificial traz melhorias inovadoras para tramitação de processos no TST. Portal Justiça do Trabalho, Tribunal Superior do Trabalho. Disponível em: https://www1.folha.uol.com.br/poder/2020/03/inteligencia-artificial-atua-como-juizmuda-estrategia-de-advogado-e-promove-estagiario.shtml?utm_source=whatsapp\&utm_ medium=social\&utm_campaign=compwa. Acesso em: 7 abr. 2020.

ITIF. What is Artificial Intelligence? In: ITIF Technology Explainer Series. Washington, 2018. Disponível em: http://www2.itif.org/2018-tech-explainerai.pdf?_ga $=2.188188648 .1526867254 .1578863290-1247635122.1578412753$. Acesso em: 12 jan. 2020.

KOURILSKY, Philippe; VINEY, Geneviève. Le príncipe de précaution: Rapport au Premier Ministre. França. 1999. Disponível em: https://www.ladocumentationfrancaise.fr/var/storage/rapports-publics/004000402.pdf. Acesso em: 6 jun. 2019.

LEMOS, Ronaldo. A proteção de dados e a Covid-19. In: ITS RIo. Rio de Janeiro, 2020. Disponível em: https://itsrio.org/pt/comunicados/a-protecao-de-dados-e-covid-19/. Acesso em: 1 abr. 2020.

LOPEZ, Teresa Ancona. Princípio da precaução e evolução da responsabilidade civil. São Paulo: Quartier Latin, 2010.

MAJONE, Giandomenico. What Price Safety? The Precautionary Principle and its Policy Implications. Journal of Common Market Studies, v. 40, n. 1, p. 89-109, 2002.

MARCHANT, Gary E.; MOSSMAN, Kenneth L. Arbitrary and Capricious: The Precautionary Principle in the European Union Courts. Washington D.C.: The AEI Press, 2004.

MCAFEE, Andrew; BRYNJOLFSSON, Erik. Big Data: The Management Revolution. Harvard Business Review, Cambridge, out. 2012. Disponível em: https://hbr.org/2012/10/big-data-the-management-revolution. Acesso em: 12 jan. 2020. 
MITTS, J. How Much Mandatory Disclosure is Effective? SSRN, 2014. Disponível em: https://papers.ssrn.com/sol3/papers.cfm?abstract_id=2404526. Acesso em: 11 ago. 2019.

NOIVILLE, Christine. Princípio da precaução e Organização Mundial do Comércio: da oposição filosófica para os ajustes técnicos? In: VARELLA, Marcelo Dias; BARROS- Ana Flávia. Princípio da precaução. Belo Horizonte: Del Rey, 2004. Coleção Direito Ambiental em Debate.

OCDE. Key points of the hearing on disruptive innovation. 2015. Disponivel em: https://one.oecd.org/document/DAF/COMP/M(2015)1/ANN8/FINAL/en/pdf\#_ga =2.165766584.788006979.1560172690-1038759775.1560172690. Acesso em: 12 jan. 2020.

PRESIDENTE do Supremo apresenta ferramentas de inteligência artificial em Londres. Portal Supremo Tribunal Federal, Assessoria de Comunicação da Presidência, [Brasília, 05 set. 2019]. Disponível em: http://www.stf.jus.br/portal/cms/verNoticiaDetalhe.asp ?idConteudo=422699. Acesso em: 7 abr. 2020.

RHODES, R. A. W. The New Governance: governing without Government. Political Studies, v. 44, p. 652-667, set. 1996. Acesso em: 13 jan. 2020.

RODOTÁ, Stefano. A vida na sociedade de vigilância. A privacidade hoje. Tradução Danilo Doneda e Laura Cabral Doneda. Rio de Janeiro: Renovar, 2008.

SABO, Isabela Cristina; ROVER, Aires José. Observância de precedentes e gestão de demandas repetitivas por meio do aprendizado de máquina. Revista Opinião Jurídica, Fortaleza, v. 18, n. 28, p. 69-93, maio/ago. 2020. doi:10.12662/24476641oj.v18i28.p69-93.2020

SANDS, Philippe. O princípio da precaução. In: VARELLA, Marcelo Dias; BARROSPLATIAU, Ana Flávia. Princípio da precaução. Coleção Direito Ambiental em Debate. Belo Horizonte: Del Rey, 2004.

SCHWAB, Klaus. A quarta Revolução Industrial. Tradução Daniel Moreira Miranda. São Paulo: Edipro, 2016.

SCHERER, Maxi. Artificial Intelligence and Legal Decision-Making: The Wide Open? Study on the Example of International Arbitration. Queen Mary School of Law Legal Studies Research Paper, n. 318, 2019. Disponível em: https://papers.ssrn.com/sol3/papers.cfm?abstract_id=3392669. Acesso em: 7 abr. 2020. p. $22-24$. 
A regulação do agir decisório disruptivo no judiciário brasileiro e a observância do princípio da precaução: juiz natural ou "juiz artificial"?

SUNSTEIN, Cass R. Laws of fear: beyond the precautionary principle. Cambridge: Cambridge University Press, 2005.

SURDEN, Harry. Machine learning and Law. Washington Law Review, v. 89, n. 1, 2014.

TEIXEIRA, Matheus. STF investe em inteligência artificial para dar celeridade a processos. Jota, [Brasília, 11 dez. 2018]. Disponível em: https://www.jota.info/coberturas-especiais/inova-e-acao/stf-aposta-inteligencia-artificialceleridade-processos-11122018. Acesso em: 7 abr. 2020.

TUREK, Matt. Explainable Artificial Intelligence (XAI). In: DARPA. [Arlington, s.d.]. Disponível em: https://www.darpa.mil/program/explainable-artificial-intelligence. Acesso em: 7 abr. 2020.

TURNER, Jacob. Robot rules: regulating artificial intelligence. Cham: Palgrave Macmillan, 2019. E-book.

UNIÃO EUROPEIA. Comunicação da Comissão (COM/2000/0001), de 2 de fevereiro de 2000, relativa ao princípio da precaução. Disponível em: https://eurlex.europa.eu/legal-content/PT/ALL/?uri=celex:52000DC0001. Acesso em: 12 jun. 2019.

UNIÃO EUROPEIA. Comunicação da Comissão (COM/2018/237), de 25 de abril de 2018, relativa a inteligência artificial para a Europa. Disponível em: https://eurlex.europa.eu/legal-content/PT/TXT/HTML/?uri=CELEX:52018DC0237\& from=EN. Acesso em: 12 jan. 2020.

UNIÃO EUROPEIA. Resolução (2019)T8-0081, do Parlamento Europeu, de sobre uma política industrial europeia completa no domínio da inteligência artificial e da robótica. Disponível em: http://www.europarl.europa.eu/doceo/document/TA-8-20190081_PT.pdf. Acesso em: 13 jan. 2020.

WALLACE, Nick; CASTRO, Daniel. The Impact of the EU's New Data Protection Regulation on AI. Washington: Center for Data Innovation, 2018. E-book.

WARREN, Samuel D.; BRANDEIS, Louis D. The right to privacy. Harvard Law Review, Boston, v. 4, n. 5, dez. 1890.

WEXLER, Rebecca. Life, Liberty, and Trade Secrets: Intellectual Property in the Criminal Justice System. Stanford Law Review, n. 1343, p. 1346-1347, 2018. Disponível em: https://papers.ssrn.com/sol3/papers.cfm?abstract_id=2920883. Acesso em: 7 abr. 2020. 


\section{NOTA}

Os Autores Rafael Gonçalves Fernandes e Liziane Paixão Silva Oliveira participaram em conjunto e de forma complementar para a concretização do presente artigo, tendo partilhado a definição do tema, dos objetivos do estudo científico, da metodologia, da orientação científica, da organização e revisão ao artigo. Coube ao Autor Rafael Gonçalves Fernandes a redação dos tópicos referentes ao levantamento histórico e técnico sobre Inteligência Artificial e coube a Autora Liziane Paixão Silva Oliveira o desenvolvimento da parte relativa ao princípio da precaução nas searas regional e internacional. $\mathrm{O}$ artigo que ora se propõe é, portanto, uma obra de cunho coletivo.

\section{Como citar este documento:}

FERNANDES, Rafael Gonçalves; OLIVEIRA, Liziane Paixão Silva. A regulação do agir decisório disruptivo no judiciário brasileiro e a observância do princípio da precaução: juiz natural ou "juiz artificial"?. Revista Opinião Jurídica, Fortaleza, v. 19, n. 30, p. 91 117 , jan./abr. 2021. 